\title{
Anion Gap Measurement
}

National Cancer Institute

\section{Source}

National Cancer Institute. Anion Gap Measurement. NCI Thesaurus. Code C74685.

The determination of the unmeasured anions (those other than the chloride and bicarbonate anions) present in a sample. 